\title{
Combination inhibition activity of chlorhexidine and antibiotics on multidrug- resistant Acinetobacter baumannii in vitro
}

\author{
Fei Lin', Bin Yu², Qinghui Wang ${ }^{3}$, Mingyong Yuan ${ }^{1}$ and Baodong Ling ${ }^{3 *}$
}

\begin{abstract}
Background: Chlorhexidine is a widely used disinfectant in clinical settings and a broad-spectrum antimicrobial agent effective against aerobic and anaerobic bacteria. However, disinfectant resistant or non-susceptible bacteria, including antibiotic-resistant Acinetobacter baumannii, have been found. This study aimed to develop a new technique to prevent and control A. baumannii infection in the hospital setting.

Methods: Chlorhexidine combined with minocycline, doxycycline, meropenem, imipenem, levofloxacin and ciprofloxacin were tested against the 30 multidrug-resistant and extremely drug-resistant A. baumannii clinical isolates. The checkerboard test was used to calculate the fractional inhibitory concentration index according to the minimum inhibitory concentration value for chlorhexidine combined with antibiotics.

Results: The combination of chlorhexidine with minocycline, doxycycline, meropenem, or ciprofloxacin showed synergistic responses in all clinical isolates, and more than $50 \%$ of isolates showed $\mathrm{FICl} \leq 0.5$. However, chlorhexidine together with imipenem or levofloxacin showed indifferent responses in 10\% and 3.33\% clinical isolates,

respectively. In all tests, combinations of chlorhexidine with each of the above six antibiotics showed synergistic and additive effects, and inhibited the clinical isolates.

Conclusions: We concluded that, chlorhexidine combined with antibiotics could be used to control the risk of infection with $A$. baumannii.
\end{abstract}

Keywords: A. baumannii, Chlorhexidine, Antibiotics, Antiseptics, In vitro

\section{Introduction}

Chlorhexidine is a bisbiguanide antiseptic, disinfectant and preservative that is effective against a wide range of bacteria, and also a broad-spectrum antimicrobial agent that is active against aerobic and anaerobic bacteria [1, 2]. It is widely used in children and adults with an excellent record of safety and efficacy for applications as diverse as hand washing, preoperative skin preparation, vaginal antisepsis, treatment of gingivitis, and body

\footnotetext{
* Correspondence: lingbaodong@cmc.edu.cn

${ }^{3}$ Sichuan Province College Key Laboratory of Structure-Specific Small

Molecule Drugs, School of Pharmacy, Chengdu Medical College, Chengdu, Sichuan, China

Full list of author information is available at the end of the article
}

washes to prevent neonatal sepsis [3-5]. Chlorhexidine acts primarily on the bacterial cell membrane causing leakage of intracellular material. Low concentrations of chlorhexidine affect membrane integrity, whereas high concentrations cause congealing of the cytoplasm [2]. One research has shown that chlorhexidine can decrease the mortality and infection rate in the hospital setting, especially in the intensive care unit [3]. However, other researches have also found that several bacteria, including A. baumannii, Klebsiella pneumoniae, Pseudomonas aeruginosa, Escherichia coli, have reduced susceptibility or are resistant to chlorhexidine [6-8].

(c) The Author(s). 2021 Open Access This article is licensed under a Creative Commons Attribution 4.0 International License, which permits use, sharing, adaptation, distribution and reproduction in any medium or format, as long as you give appropriate credit to the original author(s) and the source, provide a link to the Creative Commons licence, and indicate if changes were made. The images or other third party material in this article are included in the article's Creative Commons licence, unless indicated otherwise in a credit line to the material. If material is not included in the article's Creative Commons licence and your intended use is not permitted by statutory regulation or exceeds the permitted use, you will need to obtain permission directly from the copyright holder. To view a copy of this licence, visit http://creativecommons.org/licenses/by/4.0/ The Creative Commons Public Domain Dedication waiver (http://creativecommons.org/publicdomain/zero/1.0/) applies to the data made available in this article, unless otherwise stated in a credit line to the data. 
Table 1 Effects of biocide combinations on MDR and XDR A. baumannii isolates $(n=30)$

\begin{tabular}{|c|c|c|c|c|c|c|c|}
\hline & \multirow[t]{2}{*}{ Antibiotics } & \multicolumn{2}{|l|}{$\mathrm{FICl}$ range } & \multicolumn{4}{|l|}{ Mechanism } \\
\hline & & MDR & XDR & Synergistic & Additive & Indifferent & Antagonistic \\
\hline \multirow[t]{6}{*}{ chlorhexidine } & DOX & $0.375-1$ & $0.375-1$ & $27(90)$ & $3(10)$ & / & / \\
\hline & $\mathrm{MIN}$ & $0.375-1$ & $0.3125-1$ & $27(90)$ & $3(10)$ & / & / \\
\hline & IMP & $0.625-1.5$ & $0.3125-1.5$ & $13(43.33)$ & $14(46.67)$ & $3(10)$ & / \\
\hline & MER & $0.25-0.625$ & $0.3125-0.75$ & 29 (96.67) & $1(3.33)$ & / & / \\
\hline & LEV & $0.375-0.75$ & $0.5-1.5$ & $26(86.67)$ & $3(10)$ & $1(3.33)$ & / \\
\hline & CIP & $0.5-1$ & $0.5-1$ & 26 (86.67) & $4(13.33)$ & / & / \\
\hline
\end{tabular}

A. baumannii is an opportunistic nosocomial pathogen which can survive for prolonged periods in the hospital environment. A. baumannii causes infections including bacteremia, pneumonia, meningitis, septicemia, urinary tract infections, wound and skin infections $[9,10]$. The multidrug-resistant (MDR) and extremely-drug resistant (XDR), even the pan-drug resistant (PDR) A. baumannii have been found in hospitals. The carbapenem-resistant $A$. baumannii was identified as a priority by the World Health Organization's (WHO) report on pathogens requiring research and development of new antibiotics. An important technique to prevent and control the spread of $A$. baumannii infection in the hospital setting is to remove the bacterial cell from the surface of medical devices. In recent years, research has focused on the antimicrobial resistance and reduced biocide susceptibility of $A$. baumannii [10-12]. The chlorhexidine non- susceptibility A. baumannii in clinical isolates has been described previously [11]. In addition, chlorhexidine bathing significantly reduces colonization of $A$. baumannii in intensive care unit settings [13]. Özçaka Ö et al [14] found chlorhexidine decreases the risk of ventilator-associated pneumonia in intensive care unit patients, and A. baumannii was the most common pathogen $(64.7 \%, 27 / 34)$ of all species identified. However, whether bathing can reduce A. baumannii infections requires validation with further studies. Therefore, this study aimed to test chlorhexidine combined with antibiotics against the MDR and XDR A. baumannii isolated from clinical departments.

\section{Material and methods}

\section{Bacterial strains and media}

A. baumannii ATCC19606 was used as the wild-type strain. A total of $30 \mathrm{~A}$. baumannii clinical isolates, comprising 6 multidrug-resistant (MDR), and 24 extremelydrug resistant (XDR) isolates, were used in this study and have been described previously [11]. MuellerHinton $(\mathrm{MH})$ broth or agar (Oxoid, England) were the growth mediums used throughout the study. Bacteria were cultivated at $37^{\circ} \mathrm{C}$.

\section{Antibiotics and other agents}

The antibiotics and biocides used in this study were purchased commercially. Chlorhexidine acetate, Doxycycline (DOX), minocycline (MIN), levofloxacin (LEV), ciprofloxacin (CIP), imipenem (IMP), meropenem (MER) were purchased from Dalian Meilun Biological Technology (Dalian, China).

\section{Checkerboard test}

The interaction of chlorhexidine acetate with antibiotics was evaluated by the checkerboard method and expressed as the sum of the fractional inhibitory concentration index (FICI) for the DOX, MIN, LEV, CIP, IMP and MER. A 96 well plate was used. Briefly, $170 \mu \mathrm{l}$ of $\mathrm{MH}$ broth medium and $10 \mu \mathrm{l}$ of bacterial suspension $\left(1.5 \times 10^{8} \mathrm{CFU} / \mathrm{ml}\right)$ were added to a 96 well plate and followed by addition of $10 \mu$ l a serially diluted chlorhexidine acetate along the $\mathrm{x}$-axis and antibiotics agent on the $y$-axis. The FICI of each agent was calculated as the minimum inhibitory concentration (MIC) of the agent in combination divided by the MIC of the agent alone. The FICI was calculated in accordance with the following formula:

$$
\begin{aligned}
\mathrm{FICI}= & \mathrm{MIC}_{\mathrm{A} \text { combination }} / \mathrm{MIC}_{\mathrm{A} \text { alone }} \\
& +\mathrm{MIC}_{\mathrm{B} \text { combination }} / \mathrm{MIC}_{\mathrm{B} \text { alone }} .
\end{aligned}
$$

$\mathrm{MIC}_{\mathrm{A}}$ alone and $\mathrm{MIC}_{\mathrm{B}}$ alone are the MICs of drugs A and $\mathrm{B}$ when acting alone, $\mathrm{MIC}_{\mathrm{A}}$ combination and $\mathrm{MIC}_{\mathrm{B}}$ combination are the concentration of drug $\mathrm{A}$ and $\mathrm{B}$ in the effective combinations. In the equation, $A$ is chlorhexidine, $\mathrm{B}$ is antibiotics agents. The results were interpreted as follows: $0.5 \leq \mathrm{FICI}<1$, synergistic; $\mathrm{FICI}=1$, additive; $1<$ FICI $\leq 4$, indifferent; and FICI $>4$, antagonistic $[15$, $16]$.

\section{Results}

Checkerboard test

The checkerboard test showed the synergistic effects of biocides combined with antibiotics against the MDR and XDR A. baumannii (Table 1). Meanwhile, the MIC value of antibiotics was one to sixteen-fold decrease which 


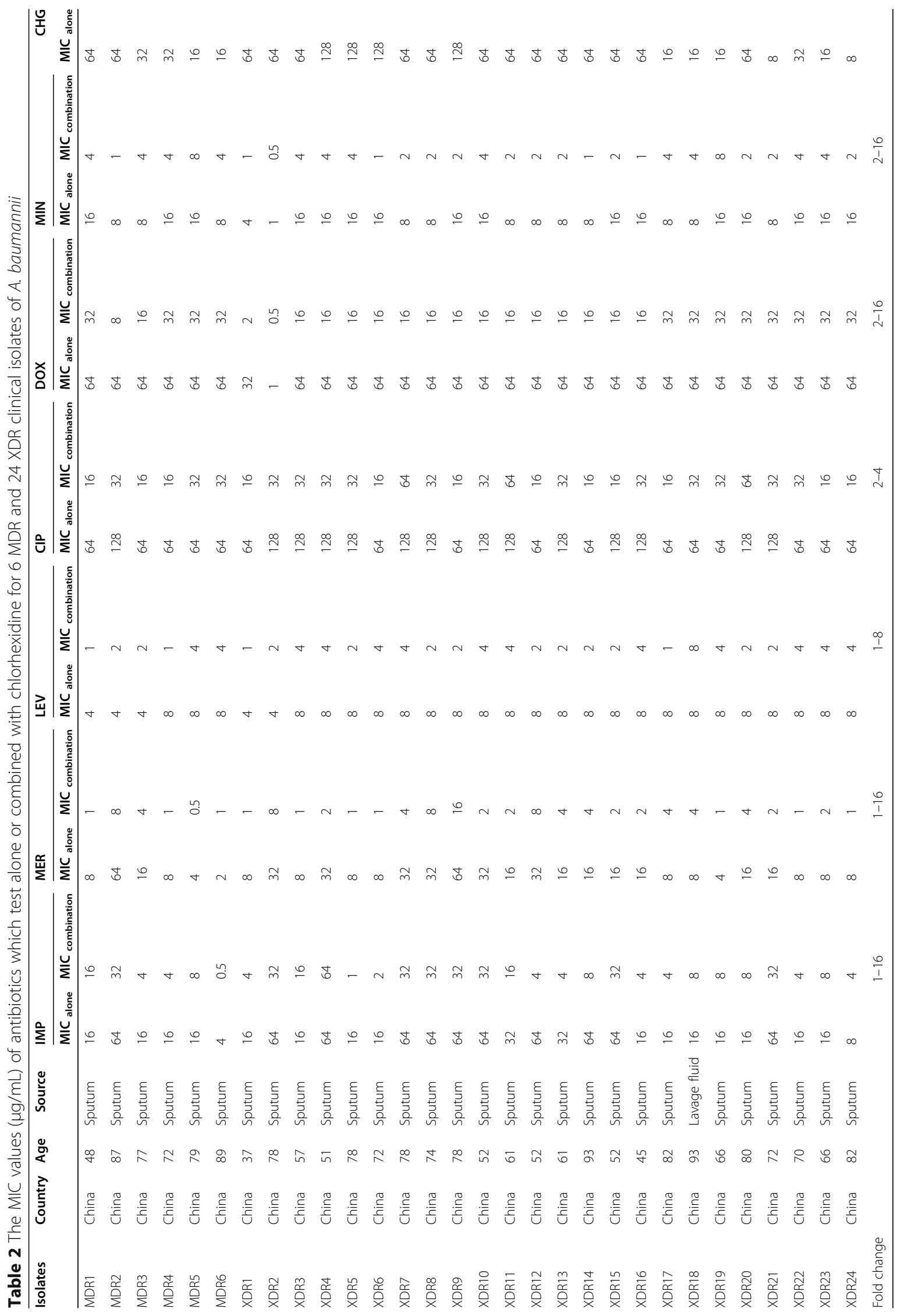


combined with chlorhexidine than alone for clinical isolates of A. baumannii (Table 2). The combinations of chlorhexidine with DOX, MIN, MER, or CIP had synergistic effects in all test isolates, as more than $50 \%$ of isolates showed the FICI $\leq 0.5$. When chlorhexidine was combined with LEX and IMP, more than $66.67 \%$ of isolates were $0.5<\mathrm{FICI} \leq 1$. However, chlorhexidine together with IMP or LEV were indifferent in only 10 and $3.33 \%$ of isolates, respectively. In all tests, chlorhexidine and the other 6 antibiotics showed synergistic and additive effects.

\section{Discussion}

A. baumannii has become a major threat in the hospital environment by causing nosocomial infections and colonization. It is inherently resistant to multiple antibiotics $[10,17]$. In the present study, MDR, XDR, PDR and biocides non-susceptible $A$. baumannii were isolated from clinical patients [11]. A. baumannii clinical isolates have been isolated from sputum samples which frequently lead to pneumonia. In a previous study, the sputum samples accounted for $89.36 \%$ of the total samples [11]. Chlorhexidine has good bactericidal effect and high safety on many bacteria. Some clinical research found chlorhexidine decreases the risk of pneumonia by maintaining good oral hygiene and body washing $[14,18]$. A recent study has shown that chlorhexidine could reduce the susceptibility to A. baumannii infection [11].

Other studies have also shown that chlorhexidine alone or in combination with other antibiotics can prevent and reduce hospital-acquired infections, including respiratory catheter, gastric tube and urinary catheter [13, 19-21]. For example, Jamal et al. [21] showed chlorhexidine alone, or combine with minocycline and rifampicin, reduced the incidence of $A$. baumannii catheterrelated infections. In this study, chlorhexidine combinations with doxycycline, minocycline, levofloxacin, ciprofloxacin, imipenem, or meropenem against 6 MDR and 24. XDR A. baumannii clinical isolates were tested in vitro. The results showed chlorhexidine combinations with DOX, MIN, MER, or CIP were synergistic in all biocide combinations, with more than $50 \%$ of isolates showing FICI $\leq 0.5$. Additionally, the chlorhexidine and antimicrobial MIC values were decreased, which indicates that this technique could effectively reduce drug resistance. However, methods for implementation in clinical settings which avoid adverse drug reactions need to be elucidated. The biocides combined with antibiotics can be used in clinical isolate inhabitation. Since chlorhexidine can be used on the body surface, it can be mixed with antibacterial drugs for disinfectant wipes used in patients' oral care, tracheal intubation and ventilators, to eliminate fixed-value bacteria and prevent the spread of infection.
The solution of IMP in normal saline solution was stable 3 to $4 \mathrm{~h}$ stored at $25^{\circ} \mathrm{C}$ [22]. MER in $0.9 \%$ saline was stable at least $7 \mathrm{~h}$ if the temperature does not increase to $22^{\circ} \mathrm{C}$, while MER stability at $5 \mathrm{~h}$ when temperature does not exceed $33^{\circ} \mathrm{C}$ [23]. Chlorhexidine combination with MER shown synergistic effects than IMP, and chlorhexidine together with IMP was indifferent in $10 \%$ of isolates. Cause IMP easy to lost activity when under test temperature. Meanwhile, solution of CIP was diluted in $0.9 \%$ sodium chloride, and the solution was stale at least 3 months when stored at room temperatures [24]. LEV was stable in $0.9 \%$ sodium chloride when stored at $25^{\circ} \mathrm{C}$ for 3 days [25]. The MIN diluted in Mueller-Hinton agar plate was instable when stored under refrigeration, and DOX also lost activity at a slower rate [26]. The LEV, CIP, DOX and MIN are stable when under test temperature. The combinations of chlorhexidine with DOX and MIN as well as LEV and CIP had the same effects in all test isolates.

\section{Conclusions}

In conclusion, Chlorhexidine combined with antibacterial drugs has synergistic or additive antibacterial effects against multiple and pan-resistant A. baumannii. This new technique may have important implications for the treatment and transmission control of A. baumannii infection.

\section{Acknowledgments Not Applicable.}

\section{Authors' contributions \\ FL and BL conceived and designed the study. FL and QW performed the experiments. FL, BY and MY analyzed the data and wrote the manuscript. All authors reviewed and approved the final version of the manuscript. \\ Funding \\ This work was supported by the National Natural Science Foundation of China (grants no. 81373454). \\ Availability of data and materials \\ The datasets used and/or analysed during the current study are available from the corresponding author on reasonable request.}

\section{Declarations}

Ethics approval and consent to participate Not applicable.

Consent for publication

Not applicable.

\section{Competing interests}

The authors declare no conflict of interest.

\section{Author details}

${ }^{1}$ Department of Pharmacy, Clinical Medical College and The First Affiliated Hospital of Chengdu Medical College, Chengdu, Sichuan, China.

${ }^{2}$ Department of Pharmacy, Mianyang Central Hospital, Mianyang, Sichuan, China. ${ }^{3}$ Sichuan Province College Key Laboratory of Structure-Specific Small Molecule Drugs, School of Pharmacy, Chengdu Medical College, Chengdu, Sichuan, China. 
Received: 17 December 2020 Accepted: 5 March 2021

Published online: 17 March 2021

\section{References}

1. Thomas, L.et al., Development of resistance to chlorhexidine diacetate in Pseudomonas aeruginosa and the effect of a 'residual' concentration. J Hosp Infect, 2000. 46(4): p. 297-303, DOl: https://doi.org/10.1053/jhin.2000. 0851.

2. McDonnell G, Russell AD. Antiseptics and disinfectants: activity, action, and resistance. Clin Microbiol Rev. 1999;12(1):147-79. https://doi.org/10.1128/ CMR.12.1.147.

3. Borer A, Gilad J, Porat N, Megrelesvilli R, Saidel-Odes L, Peled N, Eskira S, Schlaeffer F, Almog Y. Impact of $4 \%$ chlorhexidine whole-body washing on multidrug-resistant Acinetobacter baumannii skin colonisation among patients in a medical intensive care unit. J Hosp Infect. 2007;67(2):149-55. https://doi.org/10.1016/j.jhin.2007.07.023.

4. Ozcaka O, et al. Chlorhexidine decreases the risk of ventilator-associated pneumonia in intensive care unit patients: a randomized clinical trial. $J$ Periodontal Res. 2012;47(5):584-92. https://doi.org/10.1111/j.1600-0765.2012. 01470.x

5. Kim HY, Lee WK, Na S, Roh YH, Shin CS, Kim J. The effects of chlorhexidine gluconate bathing on health care-associated infection in intensive care units: a meta-analysis. J Crit Care. 2016;32:126-37. https://doi.org/10.1016/j. jcrc.2015.11.011.

6. Kawamura-Sato K, Wachino Jl, Kondo T, Ito H, Arakawa Y. Correlation between reduced susceptibility to disinfectants and multidrug resistance among clinical isolates of Acinetobacter species. J Antimicrob Chemother. 2010;65(9):1975-83. https://doi.org/10.1093/jac/dkq227.

7. Liu WJ, Fu L, Huang M, Zhang JP, Wu Y, Zhou YS, Zeng J, Wang GX. Frequency of antiseptic resistance genes and reduced susceptibility to biocides in carbapenem-resistant Acinetobacter baumannii. J Med Microbiol. 2017;66(1):13-7. https://doi.org/10.1099/jmm.0.000403.

8. Günther F, Kaiser SJ, Fries T, Frank U, Mutters NT. Susceptibility of multidrug resistant clinical pathogens to a chlorhexidine formulation. J Prev Med Hyg. 2015;56(4):E176

9. Durante-Mangoni E, Zarrilli R. Global spread of drug-resistant Acinetobacter baumannii: molecular epidemiology and management of antimicrobial resistance. Future Microbiol. 2011;6(4):407-22. https://doi.org/10.2217/ fmb.11.23.

10. Peleg AY, Seifert $H$, Paterson DL. Acinetobacter baumannii: emergence of a successful pathogen. Clin Microbiol Rev. 2008;21(3):538-82. https://doi.org/1 0.1128/CMR.00058-07.

11. Lin F, Xu Y, Chang Y, Liu C, Jia X, Ling B. Molecular characterization of reduced susceptibility to biocides in clinical isolates of Acinetobacter baumannii. Front Microbiol. 2017;8:1836. https://doi.org/10.3389/fmicb.2017. 01836.

12. Bergogne-Berezin E, Towner KJ. Acinetobacter spp. as nosocomial pathogens: microbiological, clinical, and epidemiological features. Clin Microbiol Rev. 1996;9(2):148-65. https://doi.org/10.1128/CMR.9.2.148.

13. Fan CY, Lee WT, Hsu TC, Lee CH, Wang SP, Chen WS, Huang CH, Lee CC. Effect of chlorhexidine bathing on colonization or infection with Acinetobacter baumannii: a systematic review and meta-analysis. J Hosp Infect. 2019;103(3):284-92. https://doi.org/10.1016/j.jhin.2019.08.004.

14. Özçaka Ö, Başoğlu ÖK, Buduneli N, Taşbakan MS, Bacakoğlu F, Kinane DF. Chlorhexidine decreases the risk of ventilator-associated pneumonia in intensive care unit patients: a randomized clinical trial. J Periodontal Res. 2012;47(5):584-92. https://doi.org/10.1111/j.1600-0765.2012.01470.x.

15. Lee $H$, Roh KH, Hong SG, Shin HB, Jeong SH, Song W, Uh Y, Yong D, Lee K. In vitro synergistic effects of antimicrobial combinations on extensively drug-resistant Pseudomonas aeruginosa and Acinetobacter baumannii isolates. Ann Lab Med. 2016;36(2):138-44. https://doi.org/10.3343/alm.2016.3 6.2.138.

16. Park GC, Choi JA, Jang SJ, Jeong SH, Kim CM, Choi IS, Kang SH, Park G, Moon DS. In vitro interactions of antibiotic combinations of Colistin, Tigecycline, and Doripenem against extensively drug-resistant and multidrug-resistant Acinetobacter baumannii. Ann Lab Med. 2016;36(2):12430. https://doi.org/10.3343/alm.2016.36.2.124.

17. Sheng W-H, Liao CH, Lauderdale TL, Ko WC, Chen YS, Liu JW, Lau YJ, Wang LS, Liu KS, Tsai TY, Lin SY, Hsu MS, Hsu LY, Chang SC. A multicenter study of risk factors and outcome of hospitalized patients with infections due to carbapenem-resistant Acinetobacter baumannii. Int J Infect Dis. 2010;14(9): e764-9. https://doi.org/10.1016/j.jijid.2010.02.2254.

18. Vilela MCN, et al. Oral care and nosocomial pneumonia: a systematic review. Einstein (Sao Paulo, Brazil). 2015;13(2):290-6.

19. Lewis SR, et al. Chlorhexidine bathing of the critically ill for the prevention of hospital-acquired infection. Cochrane Database Syst Rev. 2019;8: Cd012248.

20. Abbas S, Sastry S. Chlorhexidine: patient bathing and infection prevention. Curr Infect Dis Rep. 2016;18(8):25. https://doi.org/10.1007/s11908-016-0532-y.

21. Jamal MA, Rosenblatt JS, Hachem RY, Ying J, Pravinkumar E, Nates JL, Chaftari AMP, Raad II. Prevention of biofilm colonization by gram-negative bacteria on minocycline-rifampin-impregnated catheters sequentially coated with chlorhexidine. Antimicrob Agents Chemother. 2014;58(2):1179-82. https://doi.org/10.1128/AAC.01959-13.

22. Sakka SG, Glauner AK, Bulitta J̈B, Kinzig-Schippers M, Pfister W, Drusano GL, Sörgel F. Population pharmacokinetics and pharmacodynamics of continuous versus short-term infusion of imipenem-cilastatin in critically ill patients in a randomized, controlled trial. Antimicrob Agents Chemother. 2007:51(9):3304-10. https://doi.org/10.1128/AAC.01318-06.

23. Fawaz S, Barton S, Whitney L, Swinden J, Nabhani-Gebara S. Stability of Meropenem after reconstitution for administration by prolonged infusion. Hosp Pharm. 2019:54(3):190-6. https://doi.org/10.1177/0018578718779009.

24. Mathew M, Das Gupta V, Zerai T. Stability of ciprofloxacin in $5 \%$ dextrose and normal saline injections. J Clin Pharm Ther. 1994;19(4):261-2. https:// doi.org/10.1111/j.1365-2710.1994.tb00684.x.

25. Williams NA, Bornstein M, Johnson K. Stability of levofloxacin in intravenous solutions in polyvinyl chloride bags. Am J Health Syst Pharm. 1996;53(19): 2309-13. https://doi.org/10.1093/ajhp/53.19.2309.

26. Barry AL, Badal RE. Stability of minocycline, doxycycline, and tetracycline stored in agar plates and microdilution trays. Curr Microbiol. 1978;1(1):33-6. https://doi.org/10.1007/BF02601704.

\section{Publisher's Note}

Springer Nature remains neutral with regard to jurisdictional claims in published maps and institutional affiliations.

\section{Ready to submit your research? Choose BMC and benefit from:}

- fast, convenient online submission

- thorough peer review by experienced researchers in your field

- rapid publication on acceptance

- support for research data, including large and complex data types

- gold Open Access which fosters wider collaboration and increased citations

- maximum visibility for your research: over $100 \mathrm{M}$ website views per year

At $\mathrm{BMC}$, research is always in progress.

Learn more biomedcentral.com/submission 